
and Aromatic Plants

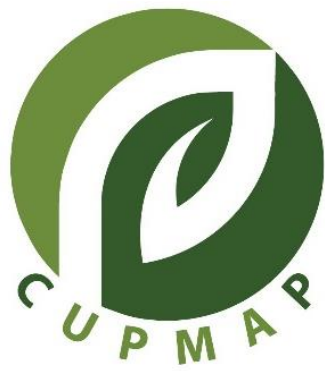

\title{
Antioxidant and Anticancer Effects of Malva verticillata Methanolic Extract
}

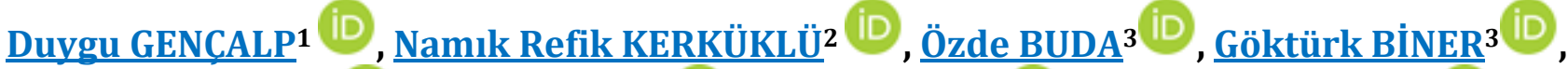

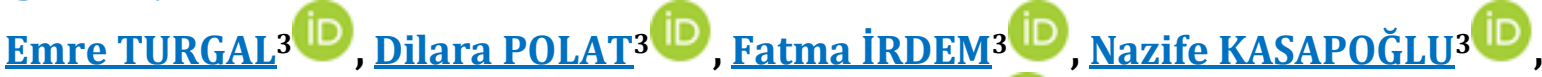 Ergül MUTLU ALTUNDAĞ ${ }^{*}$}

1Eastern Mediterranean University, Dr. Fazıl Küçük Faculty of Medicine, Department of Medical Biochemistry, Via Mersin 10, 99628, Turkey

2Eastern Mediterranean University, Faculty of Arts and Sciences, Department of Chemistry, Via Mersin 10, 99628, Turkey

${ }^{3}$ Eastern Mediterranean University, Dr. Fazll Küçük Faculty of Medicine, Via Mersin 10, 99628, Turkey

*Corresponding author: ergul.altundag@emu.edu.tr

\begin{abstract}
Objectives: Malva verticillata (M. verticillata), growing in North Cyprus, is an edible plant known as "mallow" in public. Current literature does not contain any data about the anticancer and antioxidant activities of the M. verticillata plant grows in Northern Cyprus.
\end{abstract}

Materials and Methods: In this study, M. verticillata methanolic extract was used to investigate the in vitro antioxidant and anticancer effects of the M. verticillata plant. The antioxidant potential of the Malva extract was determined using the $\alpha$-diphenyl-p-picrylhydrazyl (DPPH) free radical scavenging method, the total phenolic content (TPC) test, and the total flavonoid content (TFC) test. Besides, 3-(4,5-Dimethylthiazol-2yl)-2,5-Diphenyltetrazolium Bromide (MTT) assay was used to investigate the anticancer potential of $M$. verticillata methanolic extract on MCF-7 cells.

Results: The highest antioxidant activity of $M$. verticillata methanolic extract was found to be $69.35 \pm 3.3 \%$ at $70 \mathrm{mg} / \mathrm{ml}$. TFC and TPC contents were calculated as $502 \pm 1.8 \mu \mathrm{g} / \mathrm{mg}$ and $499 \pm 7.5 \mu \mathrm{g} / \mathrm{mg}$ extract at 70 $\mathrm{mg} / \mathrm{ml}$, respectively. Evaluation of anticancer activity revealed that MCF-7 cell proliferation was significantly inhibited with increased extract concentrations of M. verticillata.

Conclusion: In this study, methanolic extract of $M$. verticillata plant has shown to possess significant antioxidant and anticancer activity.

Key Words: Antioxidant, Anticancer, Breast cancer (MCF-7), Malva verticillata

(c) CUPMAP. All rights reserved.

\section{Introduction}

Breast cancer is known to be the primary cause of cancer death in women worldwide. Although it is rare in men, $25.4 \%$ of the total new cancer cases in women were diagnosed as breast cancer in 2018 (Bray et al., 2018).
According to a study carried out by North Cyprus Cancer Registry, Ministry of Health, breast cancer was found to be the most common cancer type for female population in North Cyprus between 2007 and 2012 (Pervaiz et al., 2017). Breast cancer can be 
treated in several ways including chemotherapy, radiation therapy, hormonal therapy and mastectomy (Maughan et al., 2010) (Radecka and Litwiniuk, 2016). However, all treatment strategies for breast cancer has some side effects and they have negative effects on patients quality of life (Taylor and Kirby, 2015) (Zurrida and Veronesi, 2015) (Klassen et al., 2017). Pain, lymphedema, hair loss, diarrhoea and peeling of skin are some of the side effects that decrease patients' quality of life. Therefore, the development of new treatment strategies with low side effects is needed to improve the survival rate of these patients. Nowadays, there is an increased interest in herbal medicine and natural products to treat diseases, and laboratory studies have gained momentum. Recent studies showed that different Malva species have anti-cancer, anti-inflammatory and antioxidant effects (Rayssan and Shawkat, 2019) (Khoury et al., 2020) (Mousavi et al., 2020) (DellaGreca et al., 2009).

M. verticillata, also known as "cluster mallow" or "Chinese mallow", is an edible plant which is a member of Malvaceae family. It grows in terrestrial habitats and it is mostly found in South East Asian countries and China (Ashok et al., 2020). Studies indicated that $M$. verticillata grows in China is a valuable source of natural antioxidants. Free radical scavenging activity of $M$. verticillata ethanol extract has been reported, and it is found to have a significant reducing power (Bao et al., 2018). In another study, water extract of $M$. verticillata seeds showed bone resorption suppression and osteoclastogenesis (Shim et al., 2016). Glycosyl glycerides isolated from the $M$. verticillata demonstrated cytotoxicity to A549, HCT-15, AGS, HepG2 cancer cells (Ko et al., 2018). However, there is no evidence about the antioxidant and anti-cancer potential of $M$. verticillata grows in North Cyprus. M. verticillata is a part of the natural flora of North Cyprus and is widely used in
Cypriot cuisine. In the current study, we aimed to evaluate the potential antioxidant and in vitro anti-cancer properties on MCF-7 cells of $M$. verticillata methanolic extract.

\section{Material and Methods}

2.1. Chemicals: Methanol (CN: 24229), Gallic acid (CN: 398225), 1,1-diphenyl-2picrylhydrazyl (DPPH, CN: D9132), Sodium carbonate (CN: 13418), Folin reagent (CN: F9252) and Quercetin (CN: Q4951)) were obtained from Sigma-Aldrich. Aluminum chloride (PC:10558030) was purchased from Thermo Fisher-Scientific.

2.2. Plant Material: Plant samples were collected from Taşkent, Kyrenia, Northern Cyprus (35.265204, 33.397465) in April 2019. Herbarium Botanists Prof. Dr. Neriman Özhatay from the Eastern Mediterranean University (EMU), Faculty of Pharmacy, identified the plant material as $M$. Verticillata. The herbarium specimen (Voucher No: DE 002) was pressed and deposited in the herbarium. Plant name was checked from http://www.theplantist.org.

\subsection{Preparation of $M$. verticillata} methanolic extract by Soxhlet extraction: Leaves of $M$. verticillata were separated carefully and washed with distilled water. Plant material was then dried at room temperature $\left(25^{\circ} \mathrm{C}\right)$ and crushed into powder. For Soxhlet extraction, 13 grams of $M$. verticillata powder and $300 \mathrm{ml}$ of methanol was used. The process was completed in a total of 16 hours; two cycles at $70{ }^{\circ} \mathrm{C}$ each lasting for eight hours. Extracts were kept in the refrigerator at $4{ }^{\circ} \mathrm{C}$ until analysis.

\subsection{Antioxidant Tests by $\alpha, \alpha$-diphenyl- $\beta$ - picrylhydrazyl (DPPH) Assay: The antioxidant activities of $M$. verticillata methanol extract were determined using a DPPH reduction method with minor modifications (Alara et al., 2018a). M. verticillata extract was dissolved in distilled}


water, and $5 \mu \mathrm{l}$ from different concentrations $(10,20,30,40$, and 70 $\mathrm{mg} / \mathrm{mL}$ ) was mixed with $195 \mu \mathrm{l}$ DPPH solution in 96-well-plate. Then, the 96-wellplate was incubated at room temperature for 30 minutes in darkness. Gallic acid solution with varying concentrations $(50,100,200$, 499,600, 800 and $1000 \mu \mathrm{g} / \mathrm{mL}$ ) was used as a standard. Following the incubation, the absorbance of the samples was measured at 517 nm with Varioskan Flash Multimode Microplate Reader (Thermo Scientific, USA). Following formula was used to calculate the inhibition percentages of the radical scavenging activity:

\section{DPPH scavenging activity (\% Inhibition) $=$ [(Acontrol-Asample) /Acontrol] x 100}

\section{Acontrol $=$ The absorbance of methanol mixed with DPPH solution \\ Asample $=$ The absorbance of $M$. verticillata extract mixed with DPPH solution}

\subsection{TPC (Total phenolic content)} Determination: To determine the TPC of $M$. verticillata extracts, Folin-Ciocalteu reagent method was used with modifications (Alara et al., 2018a) (Alara et al., 2018b). First, 50 $\mu \mathrm{l}$ from extract concentrations $(10,20,30$, 40 and $70 \mathrm{mg} / \mathrm{ml}$ ) was added into 96-well plates. Then, $100 \mu \mathrm{l}$ from folin reagent and $100 \mu \mathrm{l}$ from Na2CO3 (sodium carbonate) solution were added to reaction mixtures. Gallic acid solution with varying concentrations $(50,100,150,200,250,1000$ $\mu \mathrm{g} / \mathrm{ml}$ ) was used for the generation of the standard calibration curve $(y=0,0074 x+0,2664 ; r 2=0.978)$. Samples were incubated for 30 minutes at $25{ }^{\circ} \mathrm{C}$ prior to the absorbance measurement. Absorbance measurements were done at $765 \mathrm{~nm}$ using a Varioskan Flash Multimode Microplate Reader (Thermo Scientific, USA). The results are represented as $\mu \mathrm{g}$ gallic acid equivalent (GAE) per mg of $M$. verticillata extract ( $\mu \mathrm{g}$ $\mathrm{GAE} / \mathrm{mg}$ extract).

\subsection{TFC (Total Flavonoid Content)} Determination: AlCl3 (Aluminum chloride) colorimetric method was used to determine the TFC of the $M$. verticillata extracts with minor modifications(Kim et al., 2003). $50 \mu \mathrm{l}$ from each extract solution $(10,20,30,40$ and $70 \mathrm{mg} / \mathrm{mL}$ ) was mixed with $50 \mu \mathrm{l}$ of $2 \%$ AlCl3 in 96-well plate. Then, the reaction mixtures were incubated at room temperature for 60 minutes. Different concentrations of quercetin $(50,100,150$, 200 and $250 \mu \mathrm{g} / \mathrm{ml}$ ) were used for the generation of the standard calibration curve $(y=0,0074 x-0,0158 ; r 2=0,9709)$. At the end of the incubation period, absorbance was measured at $420 \mathrm{~nm}$ via Varioskan Flash Multimode Microplate Reader (Thermo Scientific, USA). The results were expressed as $\mu \mathrm{g}$ quercetin equivalent $(\mathrm{QE})$ per $\mathrm{mg} M$. verticillata extract ( $\mu \mathrm{g} \mathrm{QE} / \mathrm{mg}$ extract).

\subsection{MCF-7 Cell Culture and Cell Viability}

Assay: Cell culture experiment was performed on MCF-7 human breast cancer cell line obtained from the American Type Culture Collection (ATCC, HTB-22). Dulbecco's modified Eagle's medium (DMEM- Merck, Germany) supplemented with $1 \%$ L-glutamine, $1 \%$ penicillinstreptomycin, $10 \%$ fetal bovine serum (FBS; Hyclone Laboratories, USA) was used as cell culture media and cells were grown in a $5 \%$ CO2 incubator at $37{ }^{\circ} \mathrm{C}$. In order to determine the cell viability, MTT (Sigma, M2003) assay was performed (van der Heijden et al., 2004), and 5- Fluorouracil (5FU) treated group was used as a positive control. Prior to the cell viability assay, $1 \times 104$ cells/well were seeded in 96 well plates in $100 \mu \mathrm{l}$ of fresh culture medium and incubated for 24 hours at $37^{\circ} \mathrm{C}$. At the end of the incubation, cells were treated with $M$. verticillata extract at various concentrations $(5,10,20,50,100,200 \mu \mathrm{g} / \mathrm{mL})$ and $5 \mu \mathrm{M}$ Fluorouracil (5-FU) for 24 hours. Then, $10 \mu \mathrm{l}$ of $5 \mathrm{mg} / \mathrm{ml}$ MTT solution in PBS was added to each well, and left to incubate at $37^{\circ} \mathrm{C}$ for four hours. At the end of incubation period, 
the supernatant was removed, and DMSO $(100 \mu \mathrm{l})$ was added to each well. The 96-well plates were placed into a microplate shaker for 5 minutes prior to the absorbance measurement. Absorbance was measured at $570 \mathrm{~nm}$ with a Varioskan Flash Multimode Microplate Reader (Thermo Scientific, USA). The following formula was used to calculate the percentage of cell viability:

\section{$\%$ Viable cells $=($ Asample - Ablank $) /$ (Acontrol-Ablank) x 100 \\ Ablank $=$ The absorbance of blank \\ Acontrol =The absorbance of control \\ Asample $=$ The absorbance of M. verticillata extract}

The experiment was performed in triplicate, and CalcuSyn Software program (Biosoft, Ferguson, USA) was used to calculate the concentration of extract required to inhibit $50 \%$ of MCF-7 cell viability (IC50)

2.8. Statistical Analysis: Experiments were performed in triplicate and $\mathrm{P}<0.05$ was considered to be statistically significant. Test results were calculated in Microsoft Excel 2015 software (Microsoft, Redmond, USA), and results were expressed as mean \pm standard deviation (SD). GraphPad Prism Version 8 software was used to perform the statistical analyses. ANOVA/Dunnet's Multiple Comparison Test was used to determine the differences among groups.

\section{Results and Discussion}

Antioxidant activity of $M$. verticillata methanolic extract was determined by DPPH free radical scavenging assay, and reducing power of extract was determined by measuring its ability to act as a free radical scavenger. Gallic acid was used as standard and antioxidant activities of standard gallic acid concentrations at 50 and $800 \mathrm{mg} / \mathrm{ml}$ were determined as $6.13 \%$ and $91.91 \%$, respectively (data not shown). $M$. verticillata methanolic extracts demonstrated simultaneous increase in DPPH radical scavenging activities in a dose-dependent manner. DPPH radical scavenging activity was calculated as $16,3 \% \pm 4,2$ at $10 \mathrm{mg} / \mathrm{mL}$ of $M$. verticillata extract concentration. The highest DPPH scavenging activity of methanolic extract of $M$. verticillata was $69,35 \pm 3,3 \%$ at $70 \mathrm{mg} / \mathrm{mL}$. The mean percentage of DPPH free-radical scavenging activity at different concentrations of extracts is shown in Table 1 . As a basis, the total phenolic content of $M$. verticillata methanolic extract was determined using Folin-Ciocalteu reagent. The total phenolic content of the extract concentrations at 10 , $20,30,40$ and $70 \mathrm{mg} / \mathrm{ml}$ was determined as $455 \pm 14,490 \pm 6.4,492 \pm 2.4,497 \pm 2.9$ and $499 \pm 7.5 \mu \mathrm{g}$ GAE /mg extract, respectively (Table 2). Total flavonoid content of $M$. verticillata methanolic extract was determined using aluminium chloride in a colorimetric method. The results were derived from the calibration curve (Data not shown) ( $\mathrm{y}=0.0074 \mathrm{x}-0.0158, \mathrm{R} 2=0.9709)$ of quercetin (10-250 $\mu \mathrm{g} / \mathrm{mL})$ and expressed as $\mu \mathrm{g}$ Quercetin per $\mathrm{mg} M$. verticillata extract ( $\mu \mathrm{g}$ Quercetin / mg M. verticillata extract). Our results showed that flavonoid content of M. verticillata was $448 \pm 1.8 \mu \mathrm{g} / \mathrm{mg}$ quercetin equivalent at $10 \mathrm{mg} / \mathrm{mL}$ extract concentration. TFC of $20,30,40$ and 70 $\mathrm{mg} / \mathrm{mL}$ extracts was determined as $475 \pm 0.3$, $481 \pm 0.2, \quad 486 \pm 0.2$ and $502 \pm 1.8 \mu \mathrm{g} / \mathrm{mL}$, respectively (Table 3 ). To evaluate the cytotoxic effects, the methanolic extract of $M$. verticillata was subjected to MTT assay using breast cancer cell line MCF-7. MTT assay results showed concentrationdependent growth inhibition in MCF-7 breast cancer cell lines following $M$. verticillata methanolic extract $(5-200 \mu \mathrm{g} / \mathrm{ml})$ application. Results of the cytotoxicity evaluation against MCF-7 cells of the $M$. verticillata extract are shown in Figure 1. The lowest concentration $(5 \mu \mathrm{g} / \mathrm{mL})$ of the extract exhibited $22.92 \%(\mathrm{P}=0.0008)$ cell viability inhibition compared to control. In addition, increasing concentrations of the extract from $10,20,50,100$ to $200 \mu \mathrm{g} / \mathrm{mL}$ 
resulted in an increase in cell viability inhibition on MCF-7 cells from 30.22, 38.39,
46.6, $49.74 \%$ to $62.98 \%$ control $\quad(\mathrm{P}<0.0001)$, compared to

respectively.

Table 1. DPPH radical scavenging activity of the different concentrations of $M$. verticillata methanolic extract. Results are expressed as \% radical scavenging activity relative to $100 \%$ radical scavenging activity of gallic acid as a reference. Values are expressed as mean \pm standard deviation $(\mathrm{n}=3)$.

\begin{tabular}{lc}
\hline $\begin{array}{l}\text { M. verticillata extract } \\
\text { concentration (mg/mL) }\end{array}$ & $\begin{array}{c}\text { DPPH radical scavenging activity } \\
\text { (\%) }\end{array}$ \\
\hline $10 \mathrm{mg} / \mathrm{mL}$ & $16,3 \pm 4,2$ \\
$20 \mathrm{mg} / \mathrm{mL}$ & $29,67 \pm 6,5$ \\
$30 \mathrm{mg} / \mathrm{mL}$ & $29,08 \pm 2,2$ \\
$40 \mathrm{mg} / \mathrm{mL}$ & $37,84 \pm 2,3$ \\
$70 \mathrm{mg} / \mathrm{mL}$ & $69,35 \pm 3,3$ \\
\hline
\end{tabular}

Table 2. Table shows the total phenolic content of Malva verticillata extract expressed as $\mu \mathrm{g}$ gallic acid/mg of extract. Values are expressed as means \pm standard deviation $(n=3)$.

\begin{tabular}{|c|c|c|c|c|c|}
\hline & \multicolumn{5}{|c|}{ M. verticillata extract concentration $(\mathrm{mg} / \mathrm{mL})$} \\
\hline & $10 \mathrm{mg} / \mathrm{mL}$ & $20 \mathrm{mg} / \mathrm{mL}$ & $30 \mathrm{mg} / \mathrm{mL}$ & $40 \mathrm{mg} / \mathrm{mL}$ & $70 \mathrm{mg} / \mathrm{mL}$ \\
\hline GAE/mg of extract & $455 \pm 14$ & $490 \pm 6,4$ & $492 \pm 2,4$ & $497 \pm 2,9$ & $499 \pm 7,5$ \\
\hline
\end{tabular}

Table 3: Table shows the total flavonoid content of Malva verticillata extract expressed as quercetin/mg of extract. Values are expressed as means \pm standard deviation $(n=3)$.

\begin{tabular}{|c|c|c|c|c|c|}
\hline & \multicolumn{5}{|c|}{ M. verticillata extract concentration $(\mathrm{mg} / \mathrm{mL})$} \\
\hline & $10 \mathrm{mg} / \mathrm{mL}$ & $20 \mathrm{mg} / \mathrm{mL}$ & $30 \mathrm{mg} / \mathrm{mL}$ & $40 \mathrm{mg} / \mathrm{mL}$ & $70 \mathrm{mg} / \mathrm{mL}$ \\
\hline $\begin{array}{l}\mu \mathrm{g} \text { quercetin } / \mathrm{mg} \\
\text { extract }\end{array}$ & $448 \pm 1.8$ & $475 \pm 0.3$ & $481 \pm 0.2$ & $486 \pm 0.2$ & $502 \pm 1.8$ \\
\hline
\end{tabular}

Positive control $5 \mu \mathrm{M} 5$-FU was found to decrease cell viability by $50.48 \%$ $(\mathrm{P}<0.0001)$. Furthermore, methanolic extract of $M$. verticillata exhibited significant cell viability inhibition against the MCF-7 cells with an IC50 value of $71.39 \mu \mathrm{g} / \mathrm{mL}$ at
24 hours. Some medicinal plants have attracted attention as alternative cancer therapies because of their low toxicity and ease of affordability (Cassileth and Chapman, 1996). The discovery of novel potential products from bioactive plant 
extracts for cancer treatment is the subject of various researches. The current study is focused on gathering information about the antioxidant activity of the $M$. verticillata and demonstrating the potential anticancer effect on MCF-7 breast cancer cell line.

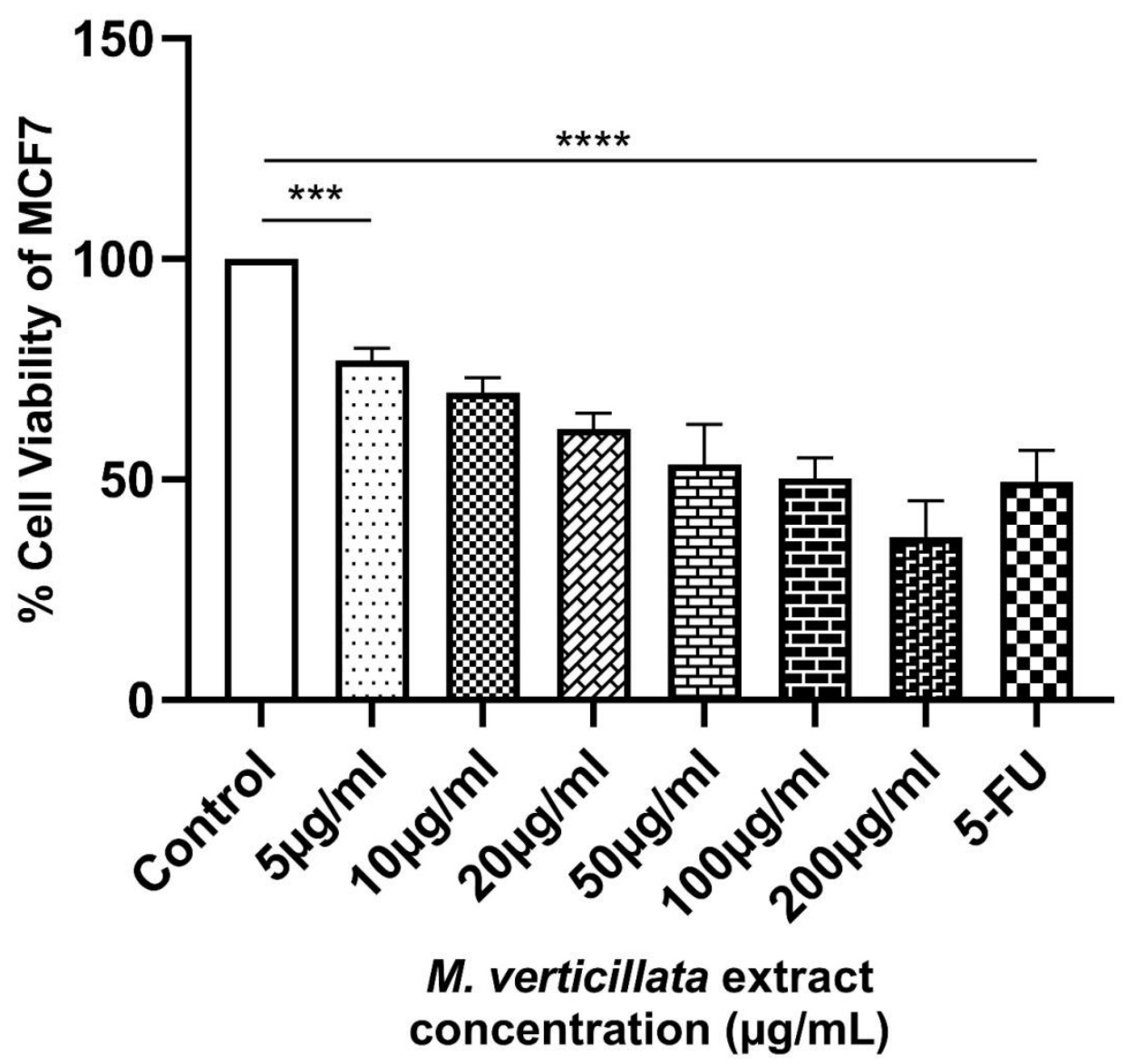

Figure 1: Effects of $M$. verticillata on MCF-7 cell viability. MCF-7 breast cancer cells were treated with different concentrations of $M$. verticillata methanol extract for 24 hours $\left(\mathrm{p}=0.0008^{* * *}, \mathrm{p}<0,0001^{* * * *}\right)$.

In this study, DPPH, TPC, and TFC tests were used to determine the antioxidant potential of $M$. verticillata methanolic extract. Previous studies have shown that other subtypes of the Malvaceae family have significant DPPH radical scavenging activity, high amount of total phenolic and total flavonoid contents (DellaGreca et al., 2009) (Güder and Korkmaz, 2012) (Choukri Beghdad et al., 2014). In one study, DPPH radical scavenging activity of $M$. verticillata leaves, seed and stem was reported (Bao et al., 2018). Based on our experimental results, $M$. verticillata methanolic leaf extract was found to have $29.67 \%$ DPPH scavenging activity at $20 \mathrm{mg} / \mathrm{mL}$. Total phenolic content evaluation also revealed phenolic content of the extract to be between $455 \pm 14$ to $499 \pm 7.5 \mu \mathrm{g}$ GAE /mg extract. The results suggest that $M$. verticillata methanolic extract has the potential antioxidant capability. Previous studies also reported that phenolic components have anticancer properties and capability to inhibit different types of cancer formation (Carocho and Ferreira, 2013) (Benetou et al., 2008) (Chahar et al., 2011). To understand the cytotoxicity effect of $M$. verticillata methanolic extract on breast cancer cells, MCF-7 cell line was selected to be 
investigated throughout this study. Earlier findings support that $M$. sylvestris methanolic leaves extract inhibits cell viability of lymphoma cells by $68.65 \%$ and melanoma cells by $76.53 \%$ at $200 \mu \mathrm{g} / \mathrm{mL}$ concentration (Rayssan and Shawkat, 2019). Similarly, in this study, $M$. verticillata methanolic extract exhibited comparable effect with $M$. sylvestris and inhibited the MCF-7 cell viability by $62.98 \%$ at 200 $\mu \mathrm{g} / \mathrm{mL}$ extract concentration. As a result, we investigated the potential antioxidant and anticancer properties of $M$. verticillata which grows in North Cyprus, for the first time. The present findings provide preliminary data exposing $M$. verticillata grows in North Cyprus have potent cytotoxic activity against MCF-7 cells.

\section{Conclusion}

In summary, this study provides evidence for the significant antioxidant activity and anticancer effect of $M$. verticillata methanolic extract. $M$. verticillata has the potential antioxidant properties that could be beneficial to health either as potential therapeutic agent or as a dietary component. Further studies are required in order to reveal its mechanism, investigate the anticancer effects of $M$. verticillata on different cancer cell lines. al., 2010).

\section{Acknowledgments}

\section{Conflict of Interest}

No conflict of interest was reported by the authors.

\section{References}

1. Alara, O.R., Abdurahman, N.H., Olalere, O.A., 2018a. Ethanolic extraction of bioactive compounds from Vernonia amygdalina leaf using response surface methodology as an optimization tool. J. Food Meas. Charact. 12, 1107-1122. https://doi.org/10.1007/ s11694- 018-9726-3

2. Alara, O.R., Abdurahman, N.H., Olalere, O.A., 2018b. Optimization of microwave-assisted extraction of flavonoids and antioxidants from Vernonia amygdalina leaf using response surface methodology. Food Bioprod. Process. 107, 36-48. https://doi.org/10.1016/j.fbp.2017.10.007

3. Ashok, A., Ravivarman, J., Kayalvizhi, K., 2020. Underutilized leafy vegetables of India and their pharmaceutical value to provoke human immune system. $1319 \sim$ J. Pharmacogn. Phytochem. 9. https://doi.org/10.22271/phyto.2020.v9.i3v.114 93

4. Bao, L., Bao, X., Li, P., Wang, X., Ao, W., 2018. Chemical profiling of Malva verticillata L. by UPLCQ-TOF-MSE and their antioxidant activity in vitro. J. Pharm. Biomed. Anal. 150, 420-426. https://doi.org/10.1016/j.jpba.2017.12.044

5. Benetou, V., Orfanos, P., Lagiou, P., Trichopoulos, D., Boffetta, P., Trichopoulou, A., 2008. Vegetables and fruits in relation to cancer risk: Evidence from the Greek EPIC cohort study. Cancer Epidemiol. Biomarkers Prev. 17, 387-392. https://doi.org/10.1158/1055-9965.EPI-07-2665

6. Bray, F., Ferlay, J., Soerjomataram, I., Siegel, R.L., Torre, L.A., Jemal, A., 2018. Global cancer statistics 2018: GLOBOCAN estimates of incidence and mortality worldwide for 36 cancers in 185 countries. CA. Cancer J. Clin. 68, 394-424. https://doi.org/10.3322/caac.21492

7. Carocho, M., Ferreira, I., 2013. The Role of Phenolic Compounds in the Fight against Cancer A Review. Anticancer. Agents Med. Chem. 13, 1236-1258. https://doi.org/10.2174/ 18715206113139990301

8. Cassileth, B.R., Chapman, C.C., 1996. Alternative and complementary cancer therapies. Cancer 77, 1026-1034. https://doi.org/10.1002/(SICI)10970142(19960315)77:6<1026::AID-

CNCR4>3.0.CO;2-F

9. Chahar, M.K., Sharma, N., Dobhal, M.P., Joshi, Y.C., 2011. Flavonoids: A versatile source of anticancer drugs. Pharmacogn. Rev. https://doi.org/10.4103/0973-7847.79093

10. Choukri Beghdad, M., Benammar, C., Bensalah, F., Sabri, F.-Z., Belarbi, M., Chemat, F., 2014. Antioxidant activity, phenolic and flavonoid content in leaves, flowers, stems and seeds of mallow (Malva sylvestris L.) from North Western of Algeria. African J. Biotechnol. 13, 486-491. https://doi.org/10.5897/AJB2013.12833

11. DellaGreca, M., Cutillo, F., D'Abrosca, B., Fiorentino, A., Pacifico, S., Zarrelli, A., 2009. Antioxidant and radical scavenging properties of Malva sylvestris. Nat. Prod. Commun. 4, 893-896. https://doi.org/10.1177/1934578x0900400702

12. Güder, A., Korkmaz, H., 2012. Evaluation of invitro antioxidant properties of hydroalcoholic solution extracts Urtica dioica L., Malva neglecta Wallr. and their mixture. Iran. J. Pharm. Res. 11, 913-923.

https://doi.org/10.22037/ijpr.2012.1159 
13. Khoury, M. El, Haykal, T., Hodroj, M.H., Najem, S.A., Sarkis, R., Taleb, R.I., Rizk, S., 2020. Malva pseudolavatera leaf extract promotes ROS induction leading to apoptosis in acute myeloid leukemia cells in vitro. Cancers (Basel). 12. https://doi.org/10.3390/cancers12020435

14.Kim, D.-O., Jeong, S.W., Lee, C.Y., 2003. Antioxidant capacity of phenolic phytochemicals from various cultivars of plums. Food Chem.81,321-326. https://doi.org/10.1016/S0308-8146(02)004235

15.Klassen, O., Schmidt, M.E., Ulrich, C.M., Schneeweiss, A., Potthoff, K., Steindorf, K., Wiskemann, J., 2017. Muscle strength in breast cancer patients receiving different treatment regimes. J. Cachexia. Sarcopenia Muscle 8, 305316. https://doi.org/10.1002/jcsm.12165

16.Ko, J.H., Cho, S.M., Joo, S.W., Kim, H.G., Lee, Y.G., Kang, S.C., Baek, N.I., 2018. Glycosyl glycerides from the aerial parts of Malva verticillata and their chemopreventive effects. Bioorg. Chem. 78, 381392. https://doi.org/10.1016/j.bioorg.2018.03.013

17.Maughan, K.L., Lutterbie, M.A., Ham, P.S., 2010. Treatment of breast cancer. Am. Fam. Physician 81, 1339-1346. https://doi.org/10.1056/nejm199810013391407

18. Mousavi, S.M., Hashemi, S.A., Zarei, M., Bahrani, S., Savardashtaki, A., Esmaeili, H., Lai, C.W., Mazraedoost, S., Abassi, M., Ramavandi, B., 2020. Data on cytotoxic and antibacterial activity of synthesized Fe304 nanoparticles using Malva sylvestris. Data $\quad \mathrm{Br}$. 28. https://doi.org/10.1016/j.dib.2019.104929

19. Pervaiz, R., Tulay, P., Faisal, F., Serakinci, N., 2017. Incidence of cancer in the turkish republic of Northern Cyprus. Turkish J. Med. Sci. 47, 523-530. https://doi.org/10.3906/sag-1510-145

20. Radecka, B., Litwiniuk, M., 2016. Breast cancer in young women. Ginekol. Pol. https://doi.org/10.5603/GP.2016.0062

21. Rayssan, R., Shawkat, M.S., 2019. Cytotoxicity Assessment of Malva Sylvestris Crude Extract on Melanoma and Lymphoma Cell Lines. J. Pharm. Sci. Res. 11, 70-74.

22.Shim, K.-S., Lee, C.-J., Yim, N.-H., Ha, H., Ma, J.Y., 2016. A water extract of Malva verticillata seeds suppresses osteoclastogenesis and bone resorption stimulated by RANK ligand. https://doi.org/10.1186/s12906-016-1295-6

23.Taylor, C.W., Kirby, A.M., 2015. Cardiac Sideeffects From Breast Cancer Radiotherapy. Clin. Oncol. 27, 621-629. https://doi.org/10.1016/j.clon.2015.06.007

24.van der Heijden, A.G., Jansen, C.F.J., Verhaegh, G., O’Donnell, M.A., Schalken, J.A., Witjes, J.A., 2004. The Effect of Hyperthermia on Mitomycin-C Induced Cytotoxicity in Four Human Bladder
Cancer Cell Lines. Eur. Urol. 46, 670-674. https://doi.org/10.1016/J.EURUR0.2004.06.009

25.Zurrida, S., Veronesi, U., 2015. Milestones in breast cancer treatment. Breast J. 21, 3-12. https://doi.org/10.1111/tbj.12361 